\section{International Scientific Journal Theoretical \& Applied Science}

\author{
p-ISSN: 2308-4944 (print) e-ISSN: 2409-0085 (online) \\ Year: $2014 \quad$ Issue: $11 \quad$ Volume: 19 \\ Published: $30.11 .2014 \quad$ http://www.T-Science.org
}

SECTION 31. Economic research, finance, innovation, risk management.

\title{
PROFITABILITY OF TECHNICAL ANALYSIS INDICATORS TO EARN ABNORMAL RETURNS IN INTERNATIONAL EXCHANGE MARKETS
}

Abstract: Technical analysis is one of the most interesting and challenging topics in recent financial science. In addition, one of the most common methods that investors use, to make investment decisions, is technical analysis strategy that uses price background knowledge and related data to forecast future prices. This study evaluates the profitability of technical analysis indicators in obtaining abnormal returns using STO, RSI, MFI, CCI, SMA indicators. Therefore, trading signal returns done by these five has been evaluated. Sample prices data Include copper, palladium, oil, gold, silver, wheat, sugar and dollar index "between beginning of 2008 to the end of 2013" by referring to transaction costs. For the statistical Calculation, we use SPSS software. The results revealed the positive returns according to technical analysis and indicator returns of technical analysis is significantly more than London Interbank Offered Rate. According to the results, STO, RSI, CCI, SMA, MFI have, in sequence, more returns and all their returns were more than London Interbank Offered Rate.

Key words: Technical Analysis; Relative Strength Index; Money Flow Index; Moving Average; Abnormal Return; LIBOR.

Language: English

Citation: Ghobadi M, Abdolbaghi A (2014) PROFITABILITY OF TECHNICAL ANALYSIS INDICATORS TO EARN ABNORMAL RETURNS IN INTERNATIONAL EXCHANGE MARKETS. ISJ Theoretical \& Applied Science 11 (19): 20-26. doi: http://dx.doi.org/10.15863/TAS.2014.11.19.5

\section{Introduction}

When the investors decided to invest in the capital markets, need to know all the variables that effect their investments and whether this investment is profitable or not. During last year's investors use "buy and hold strategy" based on fundamental analysis to analyze the investments. Technical analysis uses the past prices and related statistics to forecast investments. Technical analysis in compare to fundamental analysis has some Advantages and Disadvantages. One of these advantages is finding the best trading prices that are not possible to find that with buy and hold strategy. Finding these trading prices help the investors that trade timely and consecutively in the markets by increasing and decreasing the price speculation, therefore within a specific interval can earn abnormal returns in compare to buy and hold strategy or others trading strategy. The available findings indicate some of the trades based on technical analysis strategy that have an abnormal return, which is not justified by the financial statements and fundamental analysis.

\section{Literature}

The technical analysis origins back to Charles Dow research in early twentieth on industrials Dow Jones Averages index. His research on the market caused him realize that market trends and speculations do not simply follow financial statements and information and there are some other factors that affect the market. Those researches made a great development on the market price forecast methods. Dow Theory emerged from a collection of his articles in Wall-street journals "from (1851) to (1902)". The Dow Theory on stock price movement is a form of technical analysis that includes some aspects of sector rotation and mainly focuses on market trends. Dow Theory basis conclude that the fact prices are affected by all the information and events in the markets. All the available knowledge to market participants, including investors or fund managers affects the price. Early studies that assess the effectiveness of technical analysis considered very simple rules called filter rules. These rules involve buying a security, if it has been increased by $\mathrm{x} \%$ on the last period or selling it, if its price has 
been decreased by $\mathrm{x} \%$ on the last period. These techniques remain however very simplistic, more elaborate rules are provided by technical analysis. Some critics see technical analysis as a form of black magic. In fact, technical analysis has only recently begun to enjoy some mainstream credibility. While most analysts on Wall Street focus on the fundamental side, just about any major brokerage now employs technical analysts as well. Much of the criticism of technical analysis has its roots in academic theory - specifically the efficient market hypothesis $(\mathrm{EMH})$. This theory says that the market's price is always the correct one - any past trading information is already reflected in the price of the stock and, therefore, any analysis to find undervalued securities is useless. This is one of the reasons why academics have looked at these techniques with contempt. Several other facts have contributed to this situation. The main reason is that technical analysis violates one of the basic principles of financial theory: the efficient market hypothesis, which claims that it is impossible to predict future prices from the observation of past prices. Another reason is that a major part of these techniques cannot be tested as they are purely graphical and they do not have precise rules.

Isakov and Hollistein (1998) report abnormal returns using technical trading rules in the Swiss stock market. Though transaction costs eliminate most of the technical trading profits, they suggested conditions where large investors may profit from moving average trading rules.

Manzur and Chew (2002) test the performance of the moving average method and the Relative Strength Index (RSI), a common counter-trend indicator, on the Singapore STII from 1974 through 1994. They conclude that technical indicators can play a useful role in the timing of stock market entry and exits. They observe that the single moving average produces the best results, followed by the dual moving average and the RSI. They note that technical analysis give returns more attractive to the trading members of the stock exchange since transaction costs may tend substantially lower the gains.

Fama (1960) developed this concept into three forms of market efficiency, or the market responds to given information set. Empirical research of weakform efficiency of the market categorized as the tests of trading strategies using historical data. These statistical tests examine the correlations between historical prices changes and run testing. Ben $\mathrm{R}$ Marshall and Jared M. Cahan (2006) evaluated the profitability of CRISMA technical trading system. They collect information of companies on CRSP database in the period of January1, 1976 to December31, 2003 including 200 days of past closing prices and 20 days of past volume. They examine both long and short CRISMA filter rules in this study and found that even the system generates some profit but not consistently.

Sharif and soltanzali (2007) in a research about profitability of technical analysis indicators evaluated the Moving Average Strategy on the Tehran stock exchange markets "between (1992) to (2004)". These statistical tests examine that Moving Average Strategy is profitable, and simulation of this method can forecast the future prices.

\section{Research Hypothesis}

1. Technical analysis indicators can show the profitable trading prices.

2. Technical analysis indicators have correlations in return to show trading signals.

3. Returns of trading based on technical analysis strategy are more than London Interbank Offered Rate.

\section{Data}

Statistical data of this research Collect from LME and World Bank. data include 10560 daily prices of copper, palladium, oil, gold, silver, wheat, sugar and dollar index "between beginning of 2008 to the end of 2013"After the modification and calculation based on data filters, we obtain 2840 daily returns .

\section{Methods}

1. T-Test: It can use to determine if two sets of data are significantly different from each other, and is most commonly applied when the test statistic would follow a normal distribution if the value of a scaling term in the test statistic known.

2. Correlation: familiar examples of dependent phenomena include the correlation between the physical statures of parents and their offspring, and the correlation between the demand for a product and its price. Correlations are useful because they can indicate a predictive relationship that can exploit in practice.

3. Analysis of Variance : ANOVA is a collection of statistical models used to analyze the differences between group means and their associated procedures (such as "variation" among and between groups)

\section{Variables}

\section{Stochastic Oscillator (STO)}

Developed by George C. Lane in the late 1950s, the Stochastic Oscillator is a momentum indicator that shows the location of the close relative to the 
high-low range over a set number of periods. According to an interview with Lane, the Stochastic Oscillator "doesn't follow price, it doesn't follow volume or anything like that. It follows the speed or the momentum of price. As a rule, the momentum changes direction before price." As such, bullish and bearish divergences in the Stochastic Oscillator can be used to foreshadow reversals. This was the first, and most important, signal that Lane identified. Lane also used this oscillator to identify bull and bear setups to anticipate a future reversal. Because the Stochastic Oscillator is range bound, is also useful for identifying overbought and oversold levels. The Stochastic Oscillator measures the level of the close relative to the high-low range over a given period of time. Assume that the highest high equals 110, the lowest low equals 100 and the close equals 108 . The high-low range is 10 , which is the denominator in the $\% \mathrm{~K}$ formula. The close less the lowest low equals 8 , which is the numerator. 8 divided by 10 equals .80 or $80 \%$. Multiply this number by 100 to find $\% \mathrm{~K} \% \mathrm{~K}$ would equal 30 if the close were at $103(.30 \times 100)$. The Stochastic Oscillator is above 50 when the close is in the upper half of the range and below 50 when the close is in the lower half. Low readings (below 20 ) indicate that price is near its low for the given time period. High readings (above 80 ) indicate that price is near its high for the given time period. The IBM example above shows three 14-day ranges (yellow areas) with the closing price at the end of the period (red dotted) line. The Stochastic Oscillator equals 91 when the close was at the top of the range. The Stochastic Oscillator equals 15 when the close was near the bottom of the range. The close equals 57 when the close was in the middle of the range.

\section{Relative Strength Index (RSI)}

The Relative Strength Index (RSI) is a momentum oscillator that measures the speed and change of price movements. RSI oscillates between 0 and 100. Traditionally, and according to Wilder, RSI considered overbought when above 70 and oversold when below 30. Signals can also be generate by looking for divergences, failure swings and centerline crossovers. RSI can also use to identify the general trend. RSI considered overbought when above 70 and oversold when below 30. These traditional levels can also adjust to fit the security or analytical requirements. Rising overbought to 80 or lowering oversold to 20 will reduce the number of overbought/oversold readings. Short-term traders sometimes use 2-period RSI to look for overbought readings above 80 and oversold readings below 20 .

\section{Money Flow Index (MFI)}

The Money Flow Index (MFI) is an oscillator that uses both price and volume to measure buying and selling pressure. Created by Gene Quong and
Avrum Soudack, MFI is also known as volumeweighted RSI. MFI starts with the typical price for each period. Money flow is positive when the typical price rises (buying pressure) and negative when the typical price declines (selling pressure). Typically, MFI above 80 is considered overbought and MFI below 20 is considered oversold. Strong trends can present a problem for these classic overbought and oversold levels. MFI can become overbought $(>80)$ and prices can simply continue higher when the uptrend is strong. Conversely, MFI can become oversold $(<20)$ and prices can simply continue lower when the downtrend is strong. Quong and Soudack recommended expanding these extremes further qualify signals. A move above 90 is truly overbought and a move below 10 is truly oversold. Moves above 90 and below 10 are rare occurrences that suggest a price move is unsustainable.

\section{Simple Moving Average (SMA)}

A simple moving average is formed by computing the average price of a security over a specific number of periods. Most moving averages are based on closing prices. A 5-day simple moving average is the five-day sum of closing prices divided by five. As its name implies, a moving average is an average that moves. Old data is dropped as new data comes available. This causes the average to move along the time scale. Below is an example of a 5-day moving average evolving over three days. The first day of the moving average simply covers the last five days. The second day of the moving average drops the first data point (11) and adds the new data point (16). The third day of the moving average continues by dropping the first data point (12) and adding the new data point (17). In the example above, prices gradually increase from 11 to 17 over a total of seven days. Notice that the moving average also rises from 13 to 15 over a three-day calculation period. Also, notice that each moving average value is just below the last price.

\section{Commodity Channel Index (CCI)}

Developed by Donald Lambert and featured in Commodities magazine in 1980 , the Commodity Channel Index (CCI) is a versatile indicator that can use to identify a new trend or warn of extreme conditions. Lambert originally developed CCI to identify cyclical turns in commodities, but the indicator can successfully applied to indices, ETFs, stocks and other securities. In general, CCI measures the current price level relative to average price level over a given period. CCI is relatively high when prices are far above their average. CCI is relatively low when prices are far below their average. In this manner, CCI can use to identify overbought and oversold levels. As noted above, the majority of CCI movement occurs between -100 and +100 . A move that exceeds this range shows unusual strength or 
weakness that can foreshadow an extended move. Think of these levels as bullish or bearish filters. Technically, CCI favors the bulls when positive and the bears when negative. However, using a simple zero line crossovers can result in many whipsaws. Although entry points will lag more, requiring a move above +100 for a bullish signal and a move below -100 for a bearish signal reduces whipsaws.

Lambert set the constant at .015 to ensure that approximately 70 to 80 percent of CCI values would fall between -100 and +100 . This percentage also depends on the look-back period. A shorter CCI (10 periods) will be more volatile with a smaller percentage of values between +100 and -100 . Conversely, a longer CCI (40 periods) will have a higher percentage of values between +100 and -100 .

\section{London Interbank Offered Rate (LIBOR)}

The London Interbank Offered Rate is the average interest rate estimated by leading banks in London that the average leading bank would be charged if borrowing from other banks. Libor rates are calculated for 10 currencies and 15 borrowing periods ranging from overnight to one year and are published daily at 11:30 am (London time) by Thomson Reuters. Many financial institutions, mortgage lenders and credit card agencies set their own rates relative to it. At least $\$ 350$ trillion in derivatives and other financial products are tied to the Libor. It is the primary benchmark, along with the Euribor, for short-term interest rates around the world.

\section{Abnormal Return}

A term used to describe the returns generated by a given security or portfolio over a period of time that is different from the London Interbank Offered Rate. London Interbank Offered is kind of short-term interest rates around the world that is the theoretical rate of return of an investment with no risk of financial loss. In capital market, abnormal returns are the differences between a single stock or portfolio's performance and the expected return over a set period, Usually a London Interbank Offered Rate. For example if a stock increased by $10 \%$, but the London Interbank Offered Rate only increased by $6 \%$ and the stock has a beta of 1 , then the abnormal return was $4 \%(10 \%-6 \%=4 \%)$.

\section{Equations}

\section{Stochastic Oscillator}

1. $\% \mathrm{~K}=$ (Current Close - Lowest Low $/($ Highest High - Lowest Low) * 100

2. $\% \mathrm{D}=3$-day SMA of $\% \mathrm{~K}$

3. Lowest Low $=$ lowest low for the lookback period

4. Highest High $=$ highest high for the lookback period

5. $\% \mathrm{~K}$ is multiplied by 100 to move the decimal point two places

$$
\begin{aligned}
& \text { Relative Strength Index } \\
& \text { 1. } \mathrm{RSI}=100-\frac{100}{1+\mathrm{RS}} \\
& \text { 2. } \mathrm{RS}=\frac{\text { Average Gain }}{\text { Average Loss }} \\
& \text { 3. Average Gain }=\frac{[(\text { previous Average Gain }) \times 13+\text { current Gain }]}{14} \\
& \text { 4. Average Loss }=\frac{[(\text { previous Average Loss }) \times 13+\text { current Loss }]}{14}
\end{aligned}
$$

\section{Relative Strength Index}

\section{Money Flow Index}

1. Typical Price $=($ High + Low + Close) $/ 3$

2. Raw Money Flow $=$ Typical Price $\times$ Volume

3. Positive Money Flow $=$ Sum of positive Raw Money Flow over 14 periods.

4. Negative Money Flow $=$ Sum of negative Raw Money Flow over 14 periods.
5. Money Flow Ratio $=($ Positive Money Flow)/(Negative Money Flow)

6. Money Flow Index $=100-100 /(1+$ Money Flow Ratio)

\section{Simple Moving Average}

1. Daily Closing

Prices: 
2. First day of 5-day SMA: $(11+12+13+$ $14+15) / 5=13$

3. Second day of 5-day SMA: $(12+13+14$ $+15+16) / 5=14$

4. Third day of 5-day SMA: $(13+14+15+$ $16+17) / 5=15$

\section{Commodity Channel Index}

1. $\quad \mathrm{CCI}=($ Typical Price -20 -period SMA of TP $) /(.015 \times$ Mean Deviation $)$

2. $\quad$ Typical Price $(\mathrm{TP})=(\mathrm{High}+\mathrm{Low}+$ Close) $/ 3$

3. Constant $=.015$

\section{Abnormal Return}

1. Abnormal return $=$ Actual return Expected return

Results of First Hypothesis: Technical analysis indicators can show the profitable trading prices.

1. STO with a mean of $(0.061)$

2. RSI with a mean of $(0.055)$

3. CCI with a mean of $(0.052)$

4. MACD with a mean of $(0.048)$

5. MFI with a mean of $(0.046)$

The results provided strong support for the technical strategies. The returns obtained from these strategies were not consistent with four popular null models. Consistently, buy signals generated higher returns than sell signals, and further, the returns following buy signals were less volatile than returns following sell signals. According to confidence level, percentage 95 all the technical analysis indicators used in this research can find profitable trading prices and all the returns are more than zero.

Results of second Hypothesis: Technical analysis indicators have correlation to show trading signals.

According to the results obtained from the sample in this research (Pearson parametric correlation test): None of the technical analysis indicators has significant positive or negative correlation with each other in their returns.

Results of Third Hypothesis: Returns of trading based on technical analysis strategy is more than London Interbank Offered Rate.

We have to compare the returns for all the filters of each indicator and the returns of "London Interbank Offered Rate". The filter that generates the maximum return among all is calling the optimal filter for that stock. The summary of the results for this sub-period is describing that According to the results of the ANOVA Multiple Comparison in row: STO with a mean of (0.061), RSI with a mean of $(0.055)$, CCI with mean of $(0.052)$, MACD with a mean of (0.048), and MFI with a mean of (0.046). Each one generates an abnormal return greater than the London Interbank Offered Rate with a mean of 0.004 .

\section{CONCLUSION}

Profitability of technical analysis strategy is one of the serious subjects between the capital market investors. We can conclude that it is indeed profitable to make trading decisions based on technical indicators such as the moving average, even in the presence of transaction costs. It is even more profitable for the trading members (who effectively do not pay any commission) and large investors (who are charge very low commission). In the other part of the picture, technical trading strategies in early studies (1960-1987) were indicate to be profitable in foreign exchange markets and futures markets, but not in stock markets. Modern studies (1988-2004) indicated that technical trading strategies consistently generated economic profits in a variety of speculative markets at least until the early 1990s. Among 99 modern studies, 57 studies found positive results regarding technical trading strategies, 22 studies obtained negative results, and 20 studies indicated mixed results. However, most of these empirical studies were subject to various problems in their testing procedures, e.g. data snooping, ex post selection of trading rules or search technologies, and difficulties in estimation of risk and transaction costs.

\section{References:}

1. Audley Delory, Eccles (2003) Stock selection method: Fundamental analysis departure in the United States stock market compared and contrasted a dissertation of Ph.D. in finance. Nova Southeastern University. Economics 78, 187-202.
2. Bulkowski, Thomas (2013) Getting Started in Chart Patterns. Wiley.

3. Carmona René (2013) Statistical Analysis of Financial Data, Springer Texts in Statistics.

4. Ghobadi Mohsen (2014) Profitability of 
Technical Analysis Strategy to Earn Abnormal Returns in Tehran Stock Exchange (20072013). M.A Thesis, Islamic Azad University, Dehaghan Branch, Iran.

5. Ghobadi Mohsen (2014) Profitability of Technical Analysis Strategy to Earn Abnormal Returns in TSE (2007-2013). Paper presented at The Accounting, Economics and Financial Management Conference, Tehran, Iran, October 26-27.

6. Ghobadi Mohsen (2014) Profitability of Technical Analysis Indicators to Earn Abnormal Returns in International Exchange Markets. Paper presented at International Conference on Economic, Accounting, Management and Social Science, Szczecin, Poland, December 11.

7. Graham Benjamin (1934), Security Analysis: Sixth Edition, Foreword by Warren Buffett (Security Analysis Prior Editions), McGrawHill.
8. Lim Mark Andrew (2014) a Handbook of Technical Analysis: The Practitioner's Comprehensive Guide to Technical Analysis, Wiley, 2014.

9. Pring Martin J (2013) Technical Analysis Explained, Wiley.

10. Trabelsi, Elleuch JL (2009) Fundamental Analysis Strategy and the Prediction of Stock Returns, International Research Journal of Finance and Economics, ISSN 1450-2887, Issue 30 .

11. Tonks Hon M TI (2003) Momentum in the UK stock market, Journal of Multinational Financial Management, Title (or Abbreviated Title) of Journal, 13 (1), pp. 43-70.

12. Viskanta Tadas (2012) Abnormal Returns: Winning Strategies from the Frontlines of the Investment Blogosphere, the McGraw-Hill companies.

Table 1

Descriptive Statistics

\begin{tabular}{|c|c|c|c|c|c|c|c|}
\hline \multicolumn{9}{|c|}{ Descriptive Statistics } \\
\hline & $\mathrm{N}$ & Range & Minimum & Maximum & Sum & \multicolumn{2}{c|}{ Mean } \\
\cline { 2 - 8 } & Statistic & Statistic & Statistic & Statistic & Statistic & Statistic & Std. Error \\
\hline SMA & 551 & .860 & -.311 & .549 & 26.902 & .04882 & .004722 \\
\hline MFI & 456 & 1.165 & -.311 & .854 & 21.105 & .04628 & .005739 \\
\hline RSI & 671 & 1.225 & -.428 & .797 & 37.351 & .05566 & .004558 \\
\hline STO & 543 & 1.313 & -.455 & .881 & 44.687 & .06111 & .005548 \\
\hline LIBOR & 631 & .000 & .004 & .004 & 2.524 & .00400 & .000000 \\
\hline CCI & 846 & 1.529 & -.334 & 1.195 & 44.578 & .05269 & .004186 \\
\hline
\end{tabular}

Analysis of Variance

Table 2

\begin{tabular}{|c|c|c|c|c|c|c|}
\hline \multicolumn{9}{|c|}{ Descriptive Statistics } \\
\hline & Std. Deviation & Variance & \multicolumn{2}{c|}{ Skewness } & \multicolumn{2}{c|}{ Kurtosis } \\
\cline { 2 - 7 } & Statistic & Statistic & Statistic & Std. Error & Statistic & Std. Error \\
\hline SMA & .110830 & .012 & 1.145 & .104 & 3.830 & .208 \\
\hline MFI & .122546 & .015 & 1.731 & .114 & 7.665 & .228 \\
\hline RSI & .118067 & .014 & 1.433 & .094 & 6.166 & .188 \\
\hline STO & .130067 & .011 & 1.133 & .096 & 4.166 & .088 \\
\hline CCI & .121751 & .015 & 2.003 & .084 & 12.310 & .168 \\
\hline LIBOR & .000000 & .000 &. &. &. &. \\
\hline
\end{tabular}

T-Test

Table 3

\begin{tabular}{|c|c|c|c|c|c|c|}
\hline & \multicolumn{6}{|c|}{$95 \%$ Confidence Interval for Mean } \\
\cline { 2 - 7 } & $\mathrm{N}$ & Mean & Std. Deviation & Std. Error & Lower Bound & Upper Bound \\
\hline SMA & 551 & .0488 & .11083 & .00472 & .0395 & .0581 \\
\hline MFI & 456 & .0463 & .12255 & .00574 & .0350 & .0576 \\
\hline RSI & 671 & .0557 & .11807 & .00456 & .0467 & .0646 \\
\hline
\end{tabular}




\begin{tabular}{|c|c|c|c|c|c|c|}
\hline CCI & 846 & .0527 & .12175 & .00419 & .0445 & .0609 \\
\hline STO & 543 & .0611 & .130067 & .00554 & .0485 & .0599 \\
\hline LIBOR & 631 & .0040 & .00000 & .00000 & .0040 & .0040 \\
\hline Total & 3155 & .0420 & .10775 & .00192 & .0382 & .0457 \\
\hline
\end{tabular}

Pearson Correlation

Table 4

\begin{tabular}{|c|c|c|c|c|c|c|c|}
\hline \multicolumn{8}{|c|}{ Correlations } \\
\hline & & STO & SMA & MFI & RSI & $\mathrm{CCI}$ & LIBOR \\
\hline \multirow{3}{*}{ SMA } & Pearson Correlation & -.014 & 1 & .078 & -.016 & .034 &.$^{\mathrm{a}}$ \\
\hline & Sig. (2-tailed) & .081 & 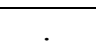 & .097 & .699 & .423 & . \\
\hline & $\mathrm{N}$ & 551 & 551 & 456 & 551 & 551 & 551 \\
\hline \multirow{3}{*}{ MFI } & Pearson Correlation & -.028 & .078 & 1 & -.034 & -.027 &.$^{\mathrm{a}}$ \\
\hline & Sig. (2-tailed) & .0441 & .097 & & .470 & .559 &. \\
\hline & $\mathrm{N}$ & 456 & 456 & 456 & 456 & 456 & 456 \\
\hline \multirow{3}{*}{ RSI } & Pearson Correlation & .019 & -.016 & -.034 & 1 & -.012 &.$^{\mathrm{a}}$ \\
\hline & Sig. (2-tailed) & .651 & .699 & .470 & & .763 & . \\
\hline & $\mathrm{N}$ & 671 & 551 & 456 & 671 & 671 & 631 \\
\hline \multirow{3}{*}{ STO } & Pearson Correlation & 1 & -.014 & -.028 & .019 & -.031 & \\
\hline & Sig. (2-tailed) & . & .081 & .0441 & .651 & .553 &.$^{\mathrm{a}}$ \\
\hline & $\mathrm{N}$ & 543 & 551 & 456 & 671 & 543 & . \\
\hline \multirow{3}{*}{$\mathrm{CCI}$} & Pearson Correlation & -.031 & .034 & -.027 & -.012 & 1 &.$^{\mathrm{a}}$ \\
\hline & Sig. (2-tailed) & .553 & .423 & .559 & .763 & . & . \\
\hline & $\mathrm{N}$ & 543 & 551 & 456 & 671 & 846 & 631 \\
\hline \multirow{3}{*}{ LIBOR } & Pearson Correlation &.$^{\mathrm{a}}$ &.$^{\mathrm{a}}$ &.$^{\mathrm{a}}$ &.$^{\mathrm{a}}$ &.$^{\mathrm{a}}$ &.$^{\mathrm{a}}$ \\
\hline & Sig. (2-tailed) & . & . & . & . &. & \\
\hline & $\mathrm{N}$ & 631 & 551 & 456 & 631 & 631 & 631 \\
\hline
\end{tabular}

